\title{
Review: papanicolaou and wet mount smears have low sensitivity but high specificity for detecting vaginal trichomoniasis
}

Wiese W,Patel SR, Patel SC, et al.A meta-analysis of the Papanicolaou smear and wet mount for the diagnosis of vaginal trichomoniasis. Am J Med 2000 Mar;108:301-8.

QUESTION: In women, what are the sensitivity and specificity of the Papanicolaou (Pap) and wet mount smears for detecting vaginal trichomoniasis?

\section{Data sources}

Studies were identified by searching Medline (1976 to February 1998) and reference lists of relevant articles.

\section{Study selection}

2 reviewers independently selected studies that described diagnostic tests for vaginal trichomoniasis, used trichomonas culture as the diagnostic standard, and were published in any language.

\section{Data extraction}

2 reviewers independently extracted data on study setting and validity of study design and for $2 \times 2$ contingency tables. The quality of study methods was classified as level I ( 2 criteria fulfilled), level II ( 1 criterion fulfilled), or level III (no criteria fulfilled). The following criteria were used: consecutive patients were evaluated prospectively, the test result did not influence the decision to apply the diagnostic test, and the test of interest and the diagnostic standard were blinded and independently examined. Disagreement was resolved by discussion.

\section{Main results}

30 studies (31 comparisons, 9501 women) met the selection criteria (level I, 12 studies; level II, 15 studies; and level III, 4 studies). 7 studies (2958 women) examined the test characteristics of the Pap smear. The pooled total prevalence was $18 \%$ (range $6 \%$ to $73 \%$ ); the table shows the weighted mean sensitivity and specificity and the likelihood ratios. All 30 studies examined the test characteristics of the wet mount smear. The pooled total prevalence was 19\% (range $6 \%$ to $73 \%$ ); the table shows the weighted mean sensitivity and specificity and the likelihood ratios.

\section{Conclusion}

The Papanicolaou and wet mount smears have low sensitivity but high specificity for detecting vaginal trichomoniasis.
Source of funding: no external funding.

For correspondence: Dr C A Estrada, East Carolina University School of Medicine, Section of General Internal Medicine, 600 Moye Boulevard, Pitt County Memorial Hospital, Teaching Annex 389, Greenville, NC 27858, USA. Fax +12528164688. estradac@mail.ecu.edu.
Test characteristics of the Papanicolaou (Pap) and wet mount smears for detecting vaginal trichomoniasis*

\begin{tabular}{|c|c|c|c|c|c|c|}
\hline Type of smear & $\begin{array}{l}\text { Number of } \\
\text { comparisons }\end{array}$ & Study quality $\dagger$ & $\begin{array}{l}\text { Weighted mean } \\
\text { sensitivity }(95 \% \mathrm{Cl})\end{array}$ & $\begin{array}{l}\text { Weighted mean } \\
\text { specificity (CI) }\end{array}$ & +LR & $-\mathrm{LR}$ \\
\hline \multirow[t]{4}{*}{ Pap } & 7 & All studies & $58 \%$ (43 to 73$)$ & $97 \%(95$ to 100$)$ & 19.3 & 0.4 \\
\hline & 3 & Level I & $57 \%(51$ to 63$)$ & $97 \%(93$ to 100$) \ddagger$ & 19.0 & 0.4 \\
\hline & 3 & Level II & $49 \%(18$ to 80$)$ & 99\% (97 to 100)‡ & 49.0 & 0.5 \\
\hline & 1 & Level III & $89 \%$ (79 to 98$)$ & $88 \%$ (71 to 100$)$ & 7.4 & 0.1 \\
\hline \multirow[t]{4}{*}{ Wet mount } & 31 & All studies & $68 \%(62$ to 74$)$ & $99.9 \%(99.8$ to 100$)$ & 680 & 0.3 \\
\hline & 12 & Level I & $58 \%(51$ to 66$) \ddagger$ & $99.8 \%(99.5$ to 100$) \ddagger$ & 290 & 0.4 \\
\hline & 15 & Level II & $72 \%(62$ to 81$) \ddagger$ & $100 \%(100)$ & $\infty$ & 0.3 \\
\hline & 4 & Level III & $82 \%(67$ to 97$) \neq$ & $100 \%(100)$ & $\infty$ & 0.2 \\
\hline
\end{tabular}

*Abbreviations defined in glossary. LRs calculated from data in article.

†Level I=high quality; level III=low quality.

$\neq$ Statistically significant heterogeneity is present.

\section{COMMENTARY}

Trichomoniasis is the second most common sexually transmitted disease in the US after human papillomavirus (HPV). ${ }^{1}$ Trichomonas infections and bacterial vaginosis have been associated with premature rupture of membranes, pelvic infections after surgery, and potential infertility, which makes treatment of these infections an appropriate public health goal. ${ }^{2}$

Wiese et al have accurately calculated the characteristics of a Pap test for trichomonads and of a wet mount to diagnose trichomoniasis from a group of studies meeting stringent criteria. The weighted averages of sensitivity and specificity are easily used in Bayes' theorem to help clinicians to decide when to test and when to treat a woman for trichomoniasis.

Clinically, the treatment threshold probability is determined by the ratio of the cost of treatment to the benefit of treatment. When the cost of trichomoniasis treatment (including adverse events and antimicrobial resistance) is low and the benefit is high, the treatment threshold probability is low (between 10\% and 20\%).

If the prevalence (or pretest probability) of trichomoniasis in the community is greater than the treatment threshold probability, then empirical treatment of all women with trichomonads on their Pap smear is appropriate. No further testing is indicated because a negative wet mount test result is not sufficiently powerful to pull the post-test probability below the treatment threshold probability.

Diane Harper, MD, MSc, MPH Dartmouth Medical School Lebanon, New Hampshire, USA

1 Cates W Jr. STD numbers higher than estimated. American Social Health Association Report, 2000. Research Triangle Park, North Carolina: American Social Health Association. http://www.ashastd.org.

2 McGregor JA, French JI, Parker R, et al. Prevention of premature birth by screening and treatment for common genital tract infections: results of a prospective controlled evaluation. AmJ Obstet Gynecol 1995;173:157-67. 